\title{
Modeling the Determinants of Time-to-Premarital Cohabitation among Women of Ethiopia: A Comparison of Various Parametric Shared Frailty Models
}

Woldemariam Erkalo Gobena ( $\nabla$ woldenegniko@gmail.com )

Mettu University

\section{Research Article}

Keywords: Survival Analysis, Premarital cohabitation, Women, Frailty, Acceleration factor

Posted Date: March 16th, 2021

DOI: https://doi.org/10.21203/rs.3.rs-291159/v1

License: (9) This work is licensed under a Creative Commons Attribution 4.0 International License.

Read Full License 


\title{
Modeling the Determinants of Time-to-Premarital Cohabitation among Women of Ethiopia: A Comparison of Various Parametric Shared Frailty \\ Models
}

\author{
Woldemariam Erkalo Gobena \\ Department of Statistics, Mettu University, Mettu, Ethiopia \\ Email: woldenegniko@gmail.com; Tel.: +251904070680; ORCID iD: 0000-0002-0215-3436
}

\begin{abstract}
Background: Premarital cohabitation is defined as the state of living together and having a sexual relationship without being married. It has become more prevalent globally in recent decades. The main objective of this study was modeling the potential risk factors of time-topremarital cohabitation among women of Ethiopia by using parametric shared frailty models where regional states of the women were used as a clustering effect in the models.

Methods: The data source for the analysis was the 2016 EDHS data. The Gamma and InverseGaussian shared frailty distributions with Exponential, Weibull, Log-logistic and Lognormal baseline models were employed to analyze risk factors associated with age at premarital cohabitation. All the fitted models were compared by using AIC values.

Results: The median age of women at premarital cohabitation was 18 years. Based on AIC values, Log-logistic-Gamma shared frailty model has smallest AIC value among the models compared. The clustering effect was significant for modeling the determinants of time-topremarital cohabitation dataset. The results showed that women's education status, occupation, pregnancy and place of residence were found to be the most significant determinants of age at premarital cohabitation whereas wealth status and religion were not significant at $5 \%$ level.
\end{abstract}


Conclusions: The Log-logistic-Gamma shared frailty model described the premarital cohabitation dataset better than other distributions used in this study. There is heterogeneity between the regions of women. Further studies should be conducted to identify other factors of age at premarital cohabitation of women in Ethiopia that were not included in this study.

Keywords: Survival Analysis; Premarital cohabitation; Women; Frailty; Acceleration factor

\section{Background}

In this study, cohabitation is defined as the state of living together and having a sexual relationship without being married [24]. It has become more prevalent globally in recent decades [25]. Different studies has been conducted in the world like in North America, Latin America, Western Europe and Eastern Europe and observed that couples exercise premarital cohabitation either as an alternative or stepping stone to marriage $[4,9,11,12,14,18,19,23]$. Premarital cohabitation is associated with higher risks of divorce compared to married couples and cohabiting couples have poor relationship skills and less predictable attitudes about marriage $[6$, 15]. Thus, the experience of cohabitation may change people's attitude about marriage and make them less strongly committed and devoted to the institution. Studies conducted previously were identified covariates of premarital cohabitation by using logistic regression. But Logistic regression does not account the censoring observations, that is, it does not hold for time-to-event data. Thus, this research aims to address the shortage of literatures by exploring covariates of time to premarital cohabitation in Ethiopia by using parametric shared frailty models. In this study, clustering (frailty) has an effect on modeling the determinants of time to premarital cohabitation, which might be due to the heterogeneity in regions. Frailty is common to all individuals in the cluster and responsible for creating dependence between event times [21]. To 
best of my knowledge, there is no any study which has been conducted in Ethiopia regarding time to premarital cohabitation. Finally, this study plays its crucial role on the formulation of effective policy to give awareness for women about the risk of premarital cohabitation on their health and marriage.

\section{Methods}

\section{Data source}

The data for this study was extracted from the published reports of Ethiopian Demographic and Health Survey (EDHS-2016) which is obtained from Central Statistical Agency [5]. It is the fourth survey conducted in Ethiopia as a part of the worldwide DHS project. The 2016 EDHS was designed to provide estimates for the health and demographic variables of interest for the following domains. Ethiopia as a whole; urban and rural areas (each as a separate domain); and 11 geographic administrative regions (9 regions and 2 city administrations), namely: Tigray, Affar, Amhara, Oromia, Somali, Benishangul-Gumuz, South Nations Nationalities and Peoples (SNNP), Gambela and Harari regional states and two city administrations, Addis Ababa and Dire Dawa. The principal objective of the 2016 EDHS was to provide current and reliable data on fertility and family planning behavior, child mortality, adult and maternal mortality, children's nutritional status, use of maternal and child health services, knowledge of HIV/AIDS, and prevalence of HIV/AIDS and anemia.

\section{Study population and variables}

The total number of sample 15,683 women between the ages of 10 years and 43 years were identified in the households of selected clusters (regions). Thus, the analysis presented in this study, on the risk factors of women's premarital cohabitation, was based on the 15,683 women. The response variable in this study is time-to-premarital cohabitation among women of Ethiopia 
which is measured in years. It is measured as the length of time from birth to age at first cohabitation. Cohabited women were event of interest for this research. The women who did not experience the event (cohabit) were censored. The following variables were considered for their influence on the time-to-premarital cohabitation of women: place of residence, education status, occupation, wealth index, pregnancy and religion.

\section{Shared Frailty Model}

Conditional on the random term, called the frailty denoted by $u_{i}$, the survival time in cluster $i(1<i<n)$ are assumed to be independent, the proportional hazard model assumes

$$
h_{i j}\left(t / X_{i j}, u_{i}\right)=\exp \left(\beta^{\prime} X_{i j}+u_{i}\right) h_{0}(t)
$$

Whereas an alternative if the proportional hazards assumption does not hold is the accelerated failure time frailty model which assumes

$$
h_{i j}\left(t / X_{i j}, u_{i}\right)=\exp \left(\beta^{\prime} X_{i j}+u_{i}\right) h_{0}\left(\exp \left(\beta^{\prime} X_{i j}+u_{i}\right) t\right)
$$

Where $i$ indicates the $i^{\text {th }}$ cluster, $j$ indicates the $j^{\text {th }}$ individual in the $i^{\text {th }}$ cluster, $h_{0}(t)$ is the baseline hazard, $u_{i}$ is the random term for all subjects in cluster $i, X_{i j}$ is the vector of covariates for subject $j$ in cluster $i$, and $\beta$ is the vector of regression coefficients. We assumed that $Z$, where $Z=\exp \left(u_{i}\right)$ has the gamma or inverse Gaussian distribution so that the hazard function depends upon this frailty that acts multiplicatively on it. The main assumption of a shared frailty model is that all individuals in cluster $i$ share the same value of frailty $Z_{i}$ ( $i=$ $1,2, \ldots, n)$, that is why the model is called the shared frailty model. The survival time is assumed to be conditionally independent with respect to the shared (common survival times) frailty. This shared frailty is the cause of dependence between survival time within the clusters $[8,13,21]$. In order to investigate the effect of the candidate covariates on time-to-premarital 
cohabitation of women, first univariable analysis has been done by fitting a separate model for each candidate covariates. Covariates that were found to be significant in the univariable analysis were included in the multivariable analysis. The multivariable survival analysis in the study was done by assuming the Exponential, Weibull, Log-normal and Log-logistic distributions for the baseline hazard function; and the Gamma and Inverse-Gaussian frailty distributions. It was performed using all the significant covariates in the univariable analysis namely place of residence, education status, occupation, wealth index, pregnancy and religion.

\section{Results and Discussions}

\section{Descriptive Statistics}

A total of 15,683 women from nine regional states and two city administrations were included in the study. The time interval between the women's date of birth and the time cohabitation took place was an interest of this study. Out of 15,683 women considered, 11,405 (72.7\%) women were experienced the event (cohabited) and the rest 4278 (27.3\%) did not experience the event. The median age at premarital cohabitation was 18 years while the minimum and maximum observed event time was 10 years and 43 years, respectively. The highest prevalence of premarital cohabitation occurred at age of 15 years, 1653 (10.5\%) women.

From Table 1, out of 15,683 women, 10,335 (65.9\%) women live in rural areas while 5,348 (34.1\%) of them live in urban. About 10,011 (63.8\%) women had no occupation and 5,672 (36.2\%) women had occupation. Out of 15,683 women, 6,413 (40.9\%) women were Orthodox religion believers, $91(0.6 \%)$ women were Catholic, $2,814(17.9 \%)$ women were Protestant, 6,209 (39.6\%) women were Muslim and 156 (1.0\%) women were from other religions. About 5,940 (37.9\%) women had poor wealth status while 2,002 (12.8\%) women had medium wealth status and 7,741 (49.4\%) 
women were rich. The study also revealed that about 7,033 (44.8\%) women had no education status while 5,213 (33.2\%) women were attended primary education, 2,238 (14.3\%) women were attended secondary school and the remaining 1,199 (7.6\%) women were attended higher education. Among cohabited women, $10292(65.6 \%)$ of them were not pregnant whereas $1113(7.1 \%)$ of them were pregnant at the time of cohabitation. Premarital cohabitation of women in Ethiopia is highly prevalent in Oromia region (1,462 (9.3\%)) followed by Amhara region (1,347 (8.6\%)) and SNNPR region $(1,293(8.2 \%))$ compared to the other regions in the country (Table 1$)$.

Table 1: Descriptive summary of time to premarital cohabitation of women dataset

\begin{tabular}{|c|c|c|c|c|}
\hline \multirow[t]{2}{*}{ Covariates } & \multirow{2}{*}{ Categories } & \multicolumn{2}{|c|}{ Status } & \multirow[b]{2}{*}{ Total (\%) } \\
\hline & & Censored (\%) & Event (\%) & \\
\hline \multirow[t]{4}{*}{ Education } & No education & $527(3.4 \%)$ & $6506(41.5 \%)$ & $7033(44.8 \%)$ \\
\hline & Primary & $2004(12.8 \%)$ & $3209(20.5 \%)$ & $5213(33.2 \%)$ \\
\hline & Secondary & $1181(7.5 \%)$ & $1057(6.7 \%)$ & $2238(14.3 \%)$ \\
\hline & Higher & $566(3.6 \%)$ & $633(4.0 \%)$ & $1199(7.6 \%)$ \\
\hline \multirow[t]{2}{*}{ Occupation } & No & $2722(17.4 \%)$ & $7289(46.5 \%)$ & $10011(63.8 \%)$ \\
\hline & Yes & $1556(9.9 \%)$ & $4116(26.2 \%)$ & $5672(36.2 \%)$ \\
\hline \multirow[t]{2}{*}{ Pregnancy } & No & $4269(27.2 \%)$ & $10292(65.6 \%)$ & $14561(92.8 \%)$ \\
\hline & Yes & $9(0.1 \%)$ & $1113(7.1 \%)$ & $1122(7.2 \%)$ \\
\hline \multirow[t]{3}{*}{ Wealth index } & Poor & $981(6.3 \%)$ & $4959(31.6 \%)$ & $5940(37.9 \%)$ \\
\hline & Middle & $470(3.0 \%)$ & $1532(9.8 \%)$ & $2002(12.8 \%)$ \\
\hline & Rich & $2827(18.0 \%)$ & $4914(31.3 \%)$ & $7741(49.4 \%)$ \\
\hline \multirow[t]{5}{*}{ Religion } & Orthodox & $2047(13.1 \%)$ & $4366(27.8 \%)$ & $6413(40.9 \%)$ \\
\hline & Catholic & $25(0.2 \%)$ & $66(0.4 \%)$ & $91(0.6 \%)$ \\
\hline & Protestant & $823(5.2 \%)$ & $1991(12.7 \%)$ & $2814(17.9 \%)$ \\
\hline & Muslim & $1364(8.7 \%)$ & $4845(30.9 \%)$ & $6209(39.6 \%)$ \\
\hline & Others & $19(0.1 \%)$ & $137(0.9 \%)$ & $156(1.0 \%)$ \\
\hline \multirow[t]{2}{*}{ Place of residence } & Urban & $2165(13.8 \%)$ & $3183(20.3 \%)$ & $5348(34.1 \%)$ \\
\hline & Rural & $2113(13.5 \%)$ & $8222(52.4 \%)$ & $10335(65.9 \%)$ \\
\hline \multirow[t]{4}{*}{ Region } & Tigray & $443(2.8 \%)$ & $1239(7.9 \%)$ & $1682(10.7 \%)$ \\
\hline & Afar & $166(1.1 \%)$ & $962(6.1 \%)$ & $1128(7.2 \%)$ \\
\hline & Amhara & $372(2.4 \%)$ & $1347(8.6 \%)$ & $1719(11.0 \%)$ \\
\hline & Oromia & $430(2.7 \%)$ & $1462(9.3 \%)$ & $1892(12.1 \%)$ \\
\hline
\end{tabular}




\begin{tabular}{llll}
\hline Somali & $302(1.9 \%)$ & $1089(6.9 \%)$ & $1391(8.9 \%)$ \\
Benishangul G. & $240(1.5 \%)$ & $886(5.6 \%)$ & $1126(7.2 \%)$ \\
SNNPR & $556(3.5 \%)$ & $1293(8.2 \%)$ & $1849(11.8 \%)$ \\
Gambela & $206(1.3 \%)$ & $829(5.3 \%)$ & $1035(6.6 \%)$ \\
Harari & $227(1.4 \%)$ & $679(4.3 \%)$ & $906(5.8 \%)$ \\
Addis Ababa & $957(6.1 \%)$ & $867(5.5 \%)$ & $1824(11.6 \%)$ \\
Dire Dawa & $379(2.4 \%)$ & $752(4.8 \%)$ & $1131(7.2 \%)$ \\
\hline
\end{tabular}

\section{Multivariable Analysis of Shared Frailty Models}

The AIC value of Log-logistic-Gamma shared frailty model (65144.36) was the smallest values among all the other AIC values of the shared frailty models indicating that Log-logistic-Gamma shared frailty model is the most efficient model to describe time-to-premarital cohabitation dataset (Table 2).

Table 2: AIC values of the parametric shared frailty models

\begin{tabular}{l|ll}
\hline \multicolumn{2}{c}{ Model } & \multirow{2}{*}{ AIC } \\
\cline { 1 - 2 } Baseline hazard function & Frailty Distribution & \\
\hline Exponential & Gamma & 94829.31 \\
& Inverse-Gaussian & 94830.34 \\
\hline Weibull & Gamma & 68763.75 \\
& Inverse-Gaussian & 68764.41 \\
\hline Log-logistic & Gamma & 65144.36 \\
& Inverse-Gaussian & 65145.87 \\
\hline Log-normal & Gamma & 65369.84 \\
& Inverse-Gaussian & 65370.31 \\
\hline
\end{tabular}

AIC=Akaike's Information Criteria

Analysis based on Log-logistic-Gamma shared frailty model showed that women's education, occupation, pregnancy and place of residence were significant whereas wealth index and religion were not significant covariates of premarital cohabitation. The survival time of premarital 
cohabitation of women shortened by a factor of $(\phi=0.714,0.455$ and 0.385$)$ for primary, secondary and higher education respectively at $5 \%$ level of significance. In other words, women who have attended at least primary school education have smaller survival time to premarital cohabitation than the reference category. The survival time of premarital cohabitation shortened by a factor of $(\phi=0.826)$ for pregnant women respectively at $5 \%$ level of significance. An acceleration factor of greater than 1 indicates prolonging the time of premarital cohabitation. Accordingly, women who had occupation $(\phi=1.095)$ and women of rural Ethiopia $(\phi=1.138)$ have prolonging time to premarital cohabitation when compared to their corresponding reference categories. In other words, they have higher expected survival time than their corresponding reference categories. The frailty in this model is assumed to follow a Gamma distribution with mean 1 and variance equal to theta $(\theta)$. The heterogeneity in the population of the region which is used as a clusters are estimated by the selected model is $\theta=0.524$ and the dependence within the clusters (region) is measured by Kendall's tau is $\tau=0.207$ (20.7\%). A variance of zero $(\theta=0)$ would indicate that the frailty component does not contribute to the model. A likelihood ratio test for the hypothesis $\theta=0$ is shown at the bottom of Table 3 and indicates that a chi-square value of 434.66 with one degree of freedom resulted a highly significant $p$ value $<0.001$. This implied that the frailty component had significant contribution to the model. The estimate of shape parameter in the Log-logistic-Gamma shared frailty model is $\gamma=8.405$. This value shows the shape of hazard function is unimodal because the value is greater than unity i.e., it increases up to some time and then decreases. (Table 3). 
Table 3: Multivariable analysis using Log-logistic-Gamma frailty model

\begin{tabular}{|c|c|c|c|c|c|}
\hline Covariates & Estimate & $\mathrm{SE}$ & $p$ value & $\phi$ & $95 \% \mathrm{CI}$ for $\phi$ \\
\hline \multicolumn{6}{|l|}{ Education } \\
\hline No education (Ref.) & 1 & & & & \\
\hline Primary & -0.337 & 0.023 & $<0.001 * * *$ & 0.714 & {$[0.669,0.759]$} \\
\hline Secondary & -0.788 & 0.037 & $<0.001 * * *$ & 0.455 & {$[0.382,0.527]$} \\
\hline Higher & -0.954 & 0.047 & $<0.001 * * *$ & 0.385 & {$[0.293,0.477]$} \\
\hline \multicolumn{6}{|l|}{ Occupation } \\
\hline No (Ref.) & 1 & & & & \\
\hline Yes & 0.091 & 0.021 & $<0.001 * * *$ & 1.095 & {$[1.054,1.136]$} \\
\hline \multicolumn{6}{|l|}{ Wealth index } \\
\hline Poor (Ref.) & 1 & & & & \\
\hline Middle & -0.013 & 0.031 & 0.677 & 0.987 & {$[0.926,1.048]$} \\
\hline Rich & -0.017 & 0.028 & 0.549 & 0.983 & {$[0.928,1.038]$} \\
\hline \multicolumn{6}{|l|}{ Pregnancy } \\
\hline No (Ref.) & 1 & & & & \\
\hline Yes & -0.191 & 0.032 & $<0.001 * * *$ & 0.826 & {$[0.763,0.889]$} \\
\hline \multicolumn{6}{|l|}{ Religion } \\
\hline \multicolumn{6}{|l|}{ Orthodox (Ref.) } \\
\hline Catholic & 0.017 & 0.125 & 0.890 & 1.017 & {$[0.772,1.262]$} \\
\hline Protestant & -0.009 & 0.035 & 0.803 & 0.991 & {$[0.922,1.060]$} \\
\hline Muslim & 0.030 & 0.029 & 0.302 & 1.030 & {$[0.974,1.087]$} \\
\hline Others & -0.094 & 0.090 & 0.296 & 0.910 & {$[0.734,1.087]$} \\
\hline \multicolumn{6}{|l|}{ Place of residence } \\
\hline Urban (Ref.) & 1 & & & & \\
\hline Rural & 0.129 & 0.033 & $<0.001 * * *$ & 1.138 & {$[1.073,1.202]$} \\
\hline$\gamma=8.405$ & $\lambda=0.112$ & \multicolumn{4}{|c|}{$\operatorname{Theta}(\theta)=0.524(\mathrm{SE}=0.026)$} \\
\hline Likelihood-ratio test of & $\operatorname{ta}=0:$ Chi & $\operatorname{are}=4$ & 4.66, P-value & $0.001 * *$ & \\
\hline
\end{tabular}

Source: EDHS 2016, Ethiopian Demographic and Health Survey Data 2016.

*significant at 5\% level, $\theta=$ Variance random effect, $\tau=$ Kendall's Tau, $\lambda=$ scale, $\gamma=$ shape, Ref. $=$ Reference Category, $S E=$ standard error of estimate, $\phi=$ Accelerated factor, $C I=$ Confidence interval

\section{Diagnostic Plots of the Parametric Baselines}

To check the adequacy of baseline hazard, the exponential is plotted by the $-\log (S(t))$ with the time of the study; the Weibull is plotted by $\log (-\log (S(t))$ with the logarithm of time of the study; the log-logistic is plotted by $\log \left(\frac{\hat{S}(t)}{1-\hat{S}(t)}\right)$ with the logarithm of time of the study and the log-normal baseline by $\phi^{-1}[1-S(t)]$ against $\log (t)$ of time of the study. If the plot is linear, 
the given baseline distribution is appropriate for this dataset (Fig. 1). The plot of log-logistic was more linear than other plots.
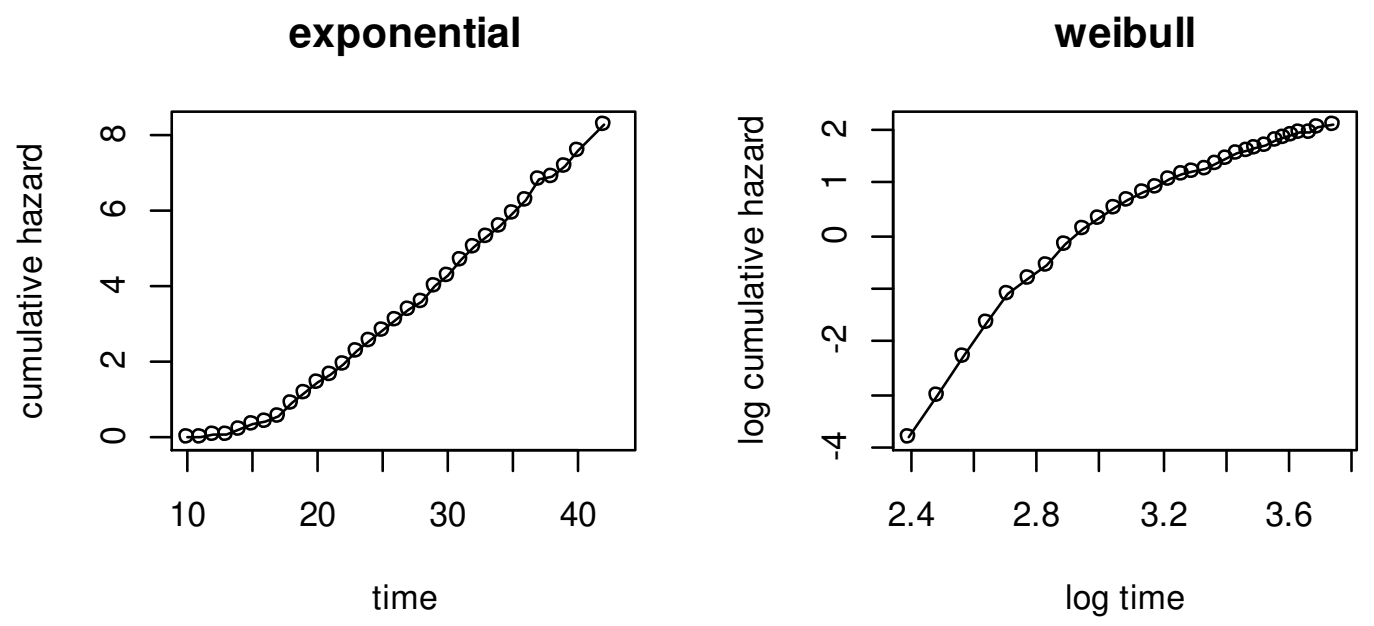

lognormal
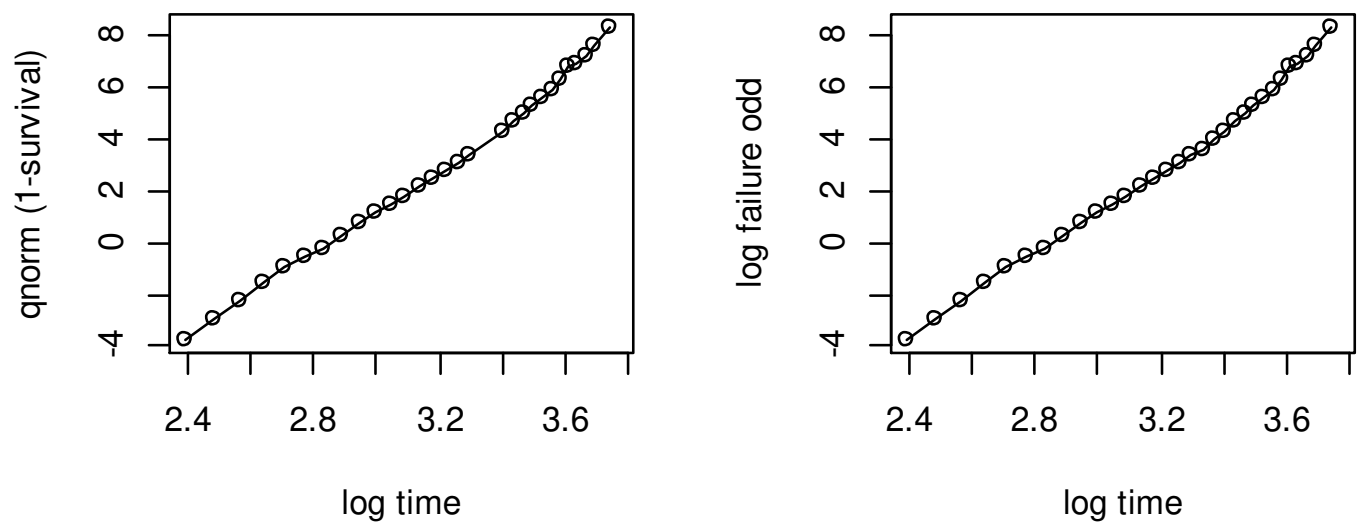

Fig.1: Graphical evolution of Exponential, Weibull, Log-normal and Log-logistic assumption

\section{The Cox Snell Residual Plots}

The Cox-Snell residuals are one way to investigate how well the model fits the data. The plot of Cox- Snell residuals is obtained for log-logistic baseline distribution to premarital cohabitation dataset (Fig.2). The plot makes straight lines through the origin for log-logistic baseline 
distribution indicating that this model describes the premarital cohabitation dataset well. This result supports the result obtained from the log failure odd plot in Fig.1

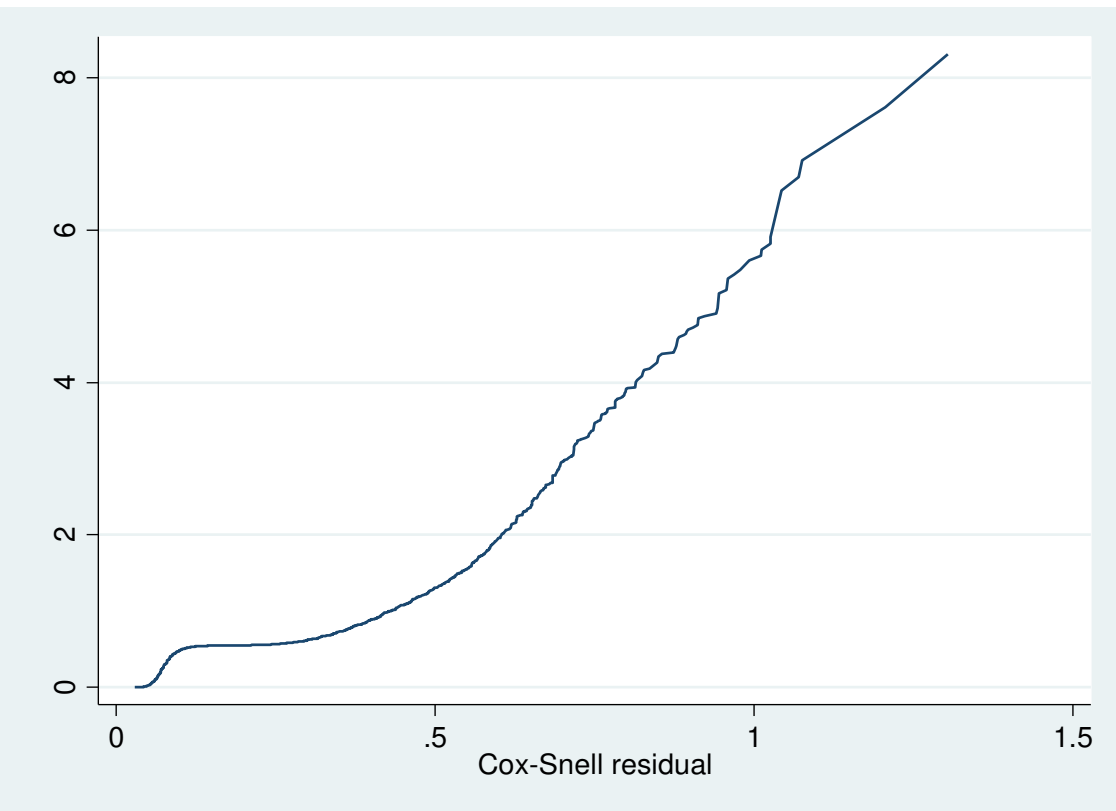

Fig.2: Cox- Snell residuals plot of Log-logistic distribution for survival time of premarital cohabitation

\section{Discussion}

The main aim of this study was modeling the determinants of time-to-premarital cohabitation among women of Ethiopia by using shared frailty models. The comparison of the models was done using the AIC criteria, where the model which has smallest AIC is chosen as best model [16]. Thus, the Log-logistic-Gamma frailty model is chosen as the best model to describe the dataset of time-to-premarital cohabitation since it has smallest AIC value of 65144.36. The dataset is obtained from EDHS 2016 after registering and requesting. In this study, region was used as a clustering (frailty) effect. The clustering effect was significant ( $p$ value $<0.001$ ) for Log-logistic-Gamma shared frailty model. This showed that there is heterogeneity between regions by assuming women within the same region share similar risk factors towards age at 
premarital cohabitation. In this study, the adequacy of baseline distributions and shared frailty models were checked by using graphs (Fig.1 and Fig.2). From the plots of baseline distributions, the plot of baseline Log-logistic was more linear than the other plots. The Cox-Snell residuals plot of Log-logistic distribution showed straight line through the origin suggesting that the model is appropriate for time-to-premarital cohabitation dataset. These findings were consistent with [3, 7, 17] for log-logistic model. The results of this study suggested that place of residence was significant predictive factor for time-to-premarital cohabitation among women of Ethiopia. This shows that women who lived in rural areas had longer survival with respect to premarital cohabitation than women who lived in urban areas. A similar study has been conducted in subSaharan Africa by [18] and revealed that urban women were more likely to cohabit compared to their rural counterparts. A significant association was found between women education and timeto-premarital cohabitation. Women who attended primary school, secondary school and higher education had significant shorter time-to-premarital cohabitation as compared to women who were not educated. This is consistent with the study conducted in Spain, the United States, subSaharan Africa and Italy by $[2,4,18,22]$ respectively and revealed that women who attended at least primary school had higher risk to be cohabited than uneducated women. The results of this study were also revealed that occupation was significant predictive factor for time-to-premarital cohabitation among women of Ethiopia. This shows that women who had occupation had longer survival with respect to premarital cohabitation than women who had not occupation. A similar study that has been conducted by $[2,22]$ revealed that women who had occupation were less vulnerable towards premarital cohabitation. A significant association was also found between pregnancy and time-to-premarital cohabitation. Women who were pregnant had significant shortened time-to-premarital cohabitation as compared to women who were not pregnant. This is 
consistent with the study conducted in Spain by [2] and revealed that pregnant women were at higher risk to be cohabited than women who were not pregnant.

\section{Conclusions}

This study was based on a dataset of age at premarital cohabitation which was obtained from Central Statistics Agency with an aim of modeling the determinants of time-to-premarital cohabitation of women by using parametric shared frailty models. The estimated median age of women at premarital cohabitation was 18 years. Based on AIC values, the Log-logistic-Gamma shared frailty model was chosen as the best model to describe premarital cohabitation dataset. There is a frailty effect on age at premarital cohabitation dataset that arises due to heterogeneity between the regions of women. Based on result of chosen model, women's educational level,

place of residence, occupation and pregnancy were significant factors of age at premarital cohabitation. Further studies should be conducted to identify other factors of age at premarital cohabitation of women in Ethiopia that were not included in this study.

\section{Abbreviations}

AIC: Akiake's Information Criteria; SNNPR: Southern Nations, Nationalities, and Peoples'

Region; SSA: Sub-Saharan Africa; EDHS: Ethiopian Demographic and Health Survey; DHS:

Demographic and Health Survey; SE: Standard Error

\section{Declarations}

Ethics approval and consent to participate: Not applicable.

Consent for publication: Not applicable

Availability of data and material: The dataset is available via http://www.dhsprogram.com/ by registering and requesting the datasets. 
Competing interests: The author declares that he has no competing interests.

Funding: No funding was obtained for this study.

Author's contributions: All the work of this research is accomplished by the author. Finally, the author drafted, read and approved the final manuscript.

Acknowledgement: I acknowledge the Ethiopian central statistical agency for providing me the data.

\section{References}

[1]. Aschalew, A., Martha, B. Law of Family. [Teaching material]. Justice and Legal Systems Research Institute, Addis Ababa. (2009)

[2]. Baizán, P., Aassve, A. \& Billari, F.C. Cohabitation, Marriage, and First Birth: The Interrelationship of Family Formation Events in Spain. European Journal of Population 19, 147-169 (2003). https://doi.org/10.1023/A:1023343001627

[3]. Bennett, S.: Analysis of survival data by the proportional odds model. Stat. Med. 2(2), 273$277(1983)$

[4]. Bumpass L, Lu HH. Trends in cohabitation and implications for children s family contexts in the United States. Popul Stud (Camb). 2000 Jan;54(1):29-41. doi: 10.1080/713779060. PMID: 28489526.

[5]. Central Statistical Agency: Ethiopian Demographic and Health Survey Addis Ababa Ethiopia (2016)

[6]. Cherlin, A.J. The deinstitutionalization of American marriage. Journal of Marriage and Family, 66: 848-861(2004). https://doi.org/10.1111/j.0022-2445.2004.00058.x

[7]. Cox, D.R.: Regression models and life tables (with discussion). J. R. Stat. Soc. Ser. B 34(2), 187 (1972)

[8]. Duchateau, L., Janssen, P.: The Frailty Model. Springer-Verlag, New York (2008). 
[9]. Esteve, Albert, Ron Lesthaeghe, and Antonio López-Gay. "The Latin American Cohabitation Boom, 1970-2007." Population and Development Review 38, no. 1 (2012): 55-81. Accessed March 2, 2021. http://www.jstor.org/stable/41857357.

[10]. Farley, A. The advantages of cohabitation in couples. (2014). Retrieved October 15, 2014, from: http://www.ehow.com/info_8448460_advantages-cohabitation-couples.html.

[11]. Fussell, Elizabeth, and Alberto Palloni. "Persistent Marriage Regimes in Changing Times." Journal of Marriage and Family 66, no. 5 (2004): 1201-213. Accessed March 2, 2021. http://www.jstor.org/stable/3600334.

[12]. Hoem, J.M., Kostova, D., Jasilioniene, A. et al. Traces of the Second Demographic Transition in Four Selected Countries in Central and Eastern Europe: Union Formation as a Demographic Manifestation. Eur J Population 25, 239-255 (2009). https://doi.org/10.1007/s10680-009-9177-y

[13]. Hougaard, P.: Analysis of Multivariate Survival Data. Springer, Berlin (2012)

[14]. Kiernan, K. Unmarried Cohabitation and Parenthood in Britain and Europe. Law \& Policy, 26: 33-55(2004). https://doi.org/10.1111/j.0265-8240.2004.00162.x

[15]. Kulu, Hill, and Paul J. Boyle. "Premarital Cohabitation and Divorce: Support for the "Trial Marriage" Theory?" Demographic Research 23 (2010): 879-904. Accessed March 2, 2021. http://www.jstor.org/stable/26349616.

[16]. Munda, Marco, Federico Rotolo, \& Catherine Legrand. "parfm: Parametric Frailty Models in R." Journal of Statistical Software [Online], 51.11 (2012): 1 - 20. Web. 2 Mar. 2021

[17]. O’Quigley, J., Stare, J.: Proportional hazards models with frailties and random effects. Stat. Med. 21, 3219-3233 (2002) 
[18]. Odimegwu, C., Ndagurwa, P., Singini, M., \& Baruwa, O. Cohabitation in Sub-Saharan Africa: A Regional Analysis. Southern African Journal of Demography, 18(1), 111-170 (2018). doi:10.2307/90022349

[19]. Prof. Leslie J. Francis, Emyr Williams \& Andrew Village (2011) Research Note: Multifaith Britain and Family Life: Changing Patterns of Marriage, Cohabitation, and Divorce among Different Faith Groups 1983-2005, Journal of Contemporary Religion, 26:1, 3341, DOI: $\underline{10.1080 / 13537903.2011 .539840}$

[20]. Rogers, H. Benefit of living together before marriage. (2009). Retrieved October 23, 2014, from: www.relating360.com/.../benefits-of-living-together-before-marriage-3-17289/

[21]. Sastry, Narayan. "A Nested Frailty Model for Survival Data, With an Application to the Study of Child Survival in Northeast Brazil." Journal of the American Statistical Association 92, no. 438 (1997): 426-35. Accessed March 2, 2021. doi:10.2307/2965690.

[22]. SCHRÖDER, CHRISTIN. "Cohabitation in Italy: Do Parents Matter?" Genus 62, no. 3/4 (2006): 53-85. Accessed March 2, 2021. http://www.jstor.org/stable/29789325.

[23]. Thornton, A., Philipov, D. Sweeping Changes in Marriage, Cohabitation and Childbearing in Central and Eastern Europe: New Insights from the Developmental Idealism Framework. Eur J Population 25, 123-156 (2009). https://doi.org/10.1007/s10680-009$\underline{9181-2}$

[24]. Uganda Bureau of Statistics (UBOS) and ICF International Inc. (2012) Uganda Demographic and Health Survey 2011. UBOS and Calverton, Kampala. ICF International Inc., Maryland. http://www.ubos.org/onlinefiles/uploads/ubos/UDHS/UDHS2011.pdf 
[25]. Yu, Jia, and Yu Xie. "Cohabitation in China: Trends and Determinants." Population and Development Review 41, no. 4 (2015): 607-28. Accessed March 1, 2021.

http://www.jstor.org/stable/24638577. 
Figures

exponential

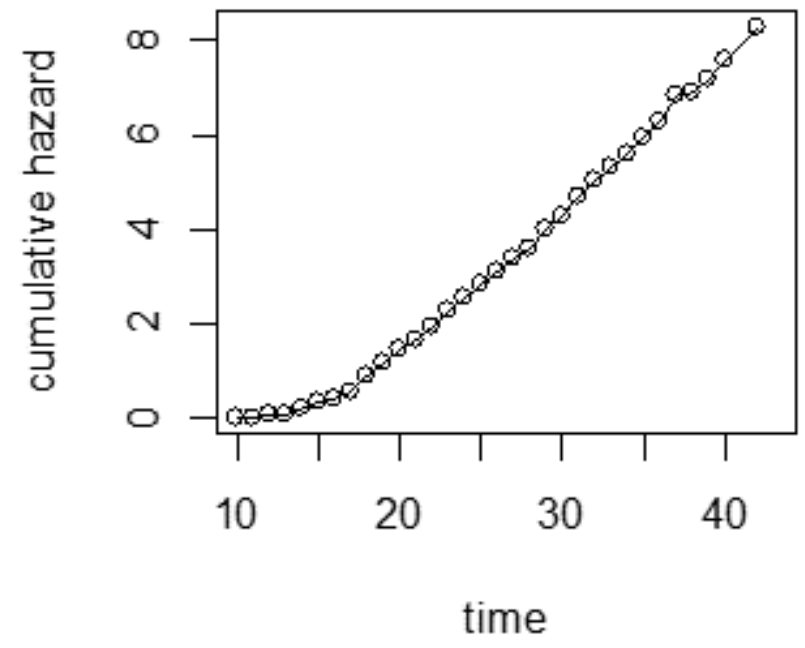

lognormal

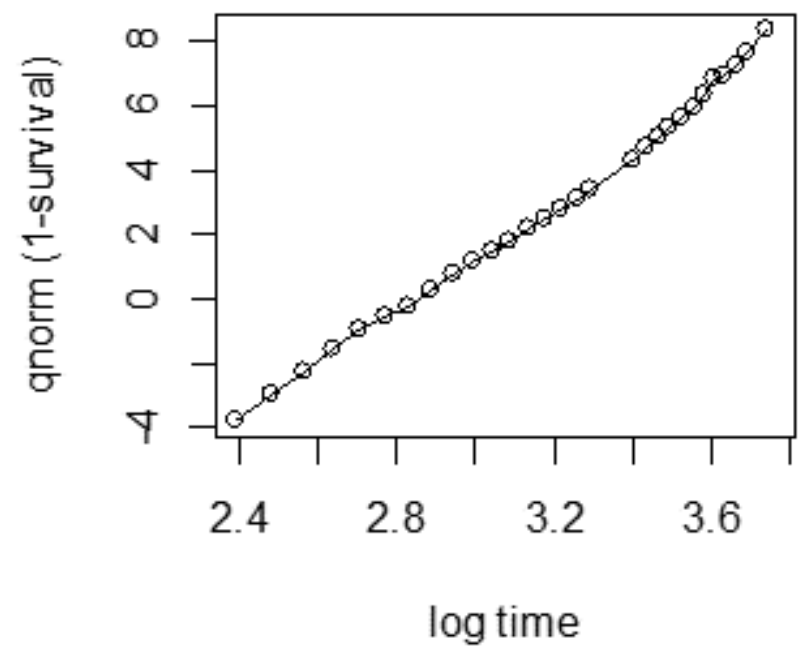

weibull

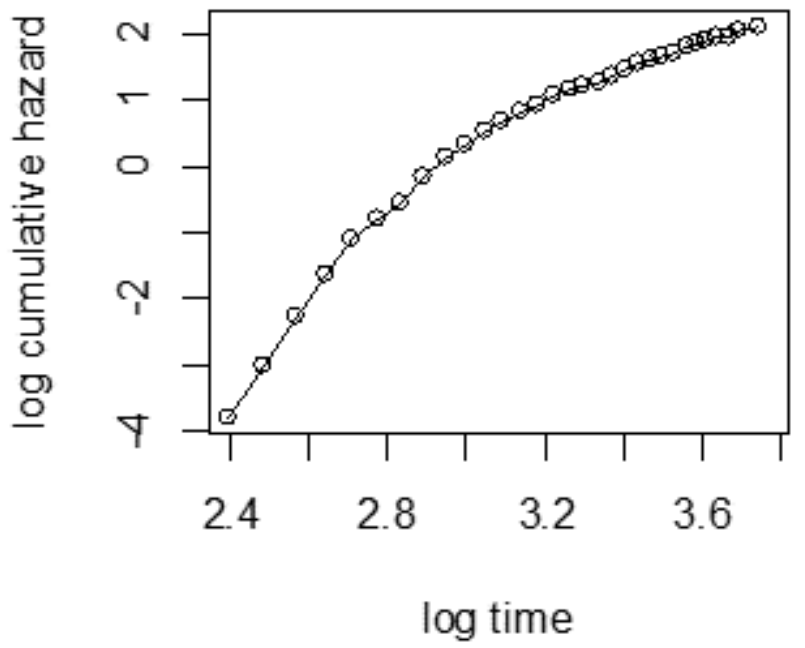

loglogistic

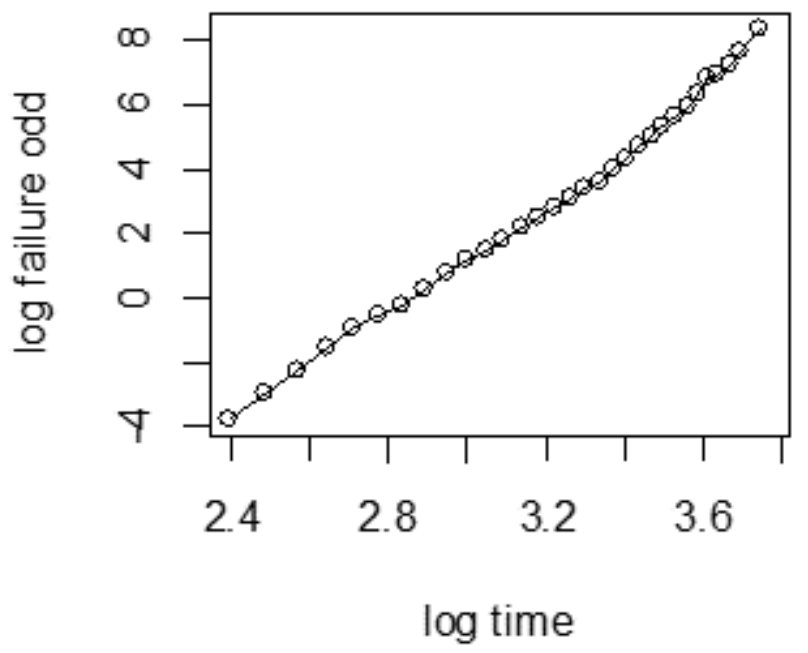

Figure 1

Graphical evolution of Exponential, Weibull, Log-normal and Log-logistic assumption 


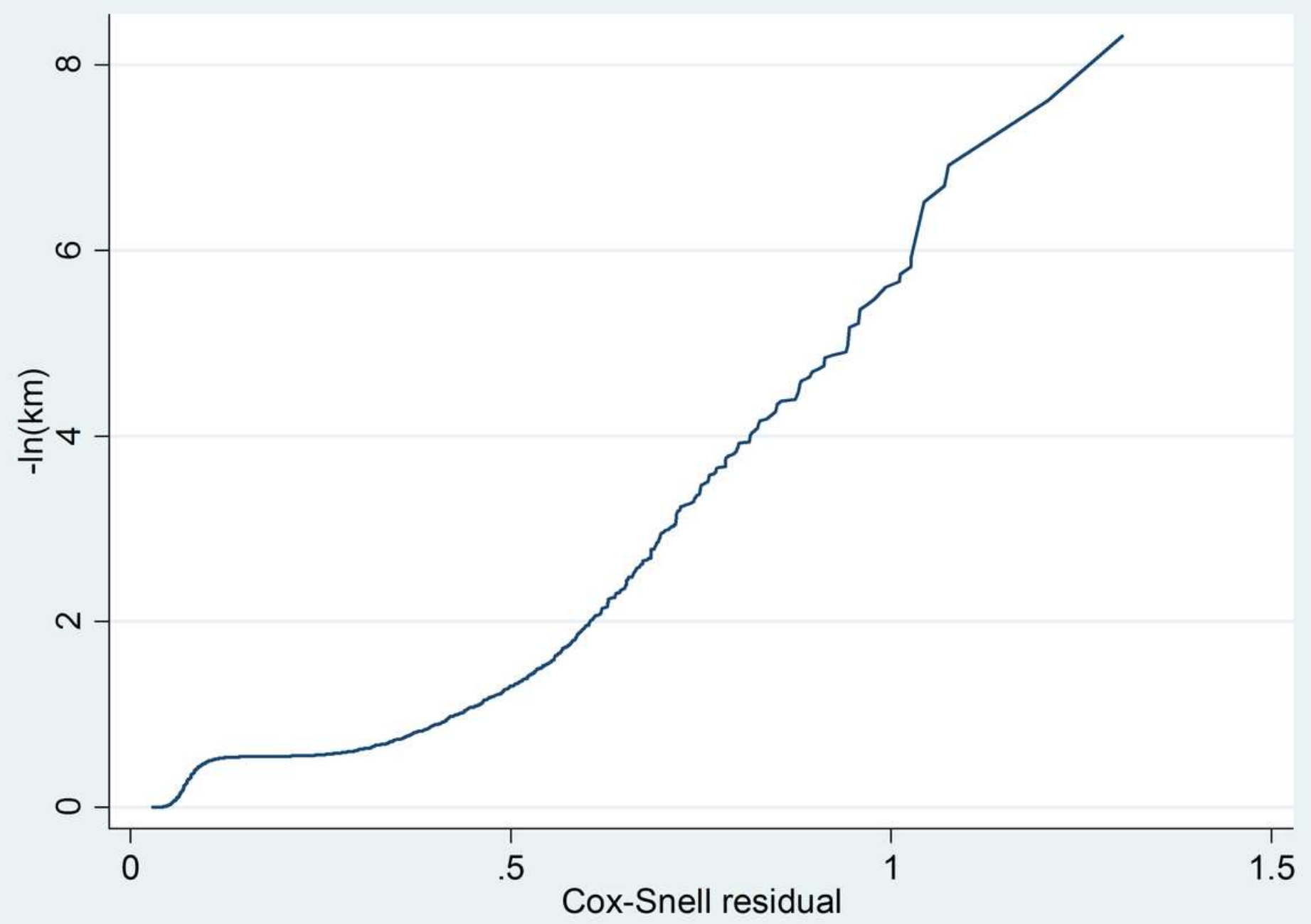

Figure 2

Cox-Snell residuals plot of Log-logistic distribution for survival time of premarital cohabitation 